\title{
Insulin regulates Presenilin 1 localization via PI3K/Akt signaling.
}

\section{AUTHOR(S):}

Maesako, Masato; Uemura, Kengo; Kubota, Masakazu; Ando, Koichi; Kuzuya, Akira; Asada, Megumi; Kihara, Takeshi; Kinoshita, Ayae

\section{CITATION:}

Maesako, Masato ...[et al]. Insulin regulates Presenilin 1 localization via PI3K/Akt signaling.. Neuroscience letters 2010, 483(3): 157-161

\section{ISSUE DATE:}

2010-10-15

URL:

http://hdl.handle.net/2433/126716

\section{RIGHT:}

(C) 2010 Elsevier Ireland Ltd; This is not the published version. Please cite only the published version.; この論文は出版社版でありません。引 用の際には出版社版をご確認ご利用ください。 


\title{
Insulin regulates Presenilin 1 localization via PI3K/Akt signaling
}

\author{
Masato Maesako, Kengo Uemura², Masakazu Kubota ${ }^{1}$, Koichi Ando ${ }^{2}$, Akira Kuzuya ${ }^{2}$, Megumi \\ Asada $^{1}$, Takeshi Kihara ${ }^{3}$ and Ayae Kinoshita ${ }^{1}$
}

1. From the School of Human Health Sciences, Kyoto University Graduate School of Medicine, Kyoto 606-8507,

2. Department of Neurology, Kyoto University Graduate School of Medicine, Kyoto 606-8507,

3. Department of Neuroscience for Drug Discovery, Kyoto University Graduate School of Pharmaceutical Sciences, Kyoto 606-8501,

The number of text pages of the whole manuscript: 17 pages

The number of figures and tables: 3 figures without tables

Address correspondence to: School of Human health Sciences, Kyoto University Graduate School of Medicine, 53, Shogoinkawahara-cho, Sakyo-ku, Kyoto 606-8507, Japan. Tel./Fax: 81-75-751-3969; Email: akinoshita@hs.med.kyoto-u.ac.jp

Acknowledgements: We greatly appreciate the gift of human Insulin Receptor (hIR) construct from Dr. T. Ikeuchi (Niigata University, Niigata, Japan). The work was financially supported by Grant-in-Aid from the Ministry of Education, Culture, Sports, Science and Technology (20300124) and the Research Grant from Takeda Science Foundation.

Key words: Alzheimer's disease, insulin, Preseninlin 1, phosphorylation, 


\section{Abstract}

Recently, insulin signaling has been highlighted in the pathology of Alzheimer's disease (AD). Although the association between insulin signaling and Tau pathology has been investigated in several studies [1-3], the interaction between insulin signaling and Presenilin 1 (PS1), a key molecule of Amyloid $\beta$ (A $\beta$ ) pathology, has not been elucidated so far. In this study, we demonstrated that insulin inhibited PS1 phosphorylation at serine residues (serine 353,357 ) via phosphatidylinositol 3-kinase (PI3K)/Akt signal pathway and strengthened the trimeric complex of PS1/N-cadherin/ $\beta$-catenin, consequently relocalizing PS1 to the cell surface. Since our recent report suggests that PS1/N-cadherin/ $\beta$-catenin complex regulates $A \beta$ production [4], it is likely that insulin signaling affects $A \beta$ pathology by regulating PS1 localization.

\section{$\underline{\text { Introduction }}$}

Alzheimer's disease (AD) is pathologically characterized by amyloid plaques and neurofibrillary tangles (NFTs). Amyloid plaques are composed of amyloid $\beta$ peptides (A $\beta)$, which are derived from the amyloid precursor protein (APP) via proteolytic cleavage, by $\gamma$-secretase [5]. $\gamma$-Secretase is an enzymatic complex composed of at least four proteins - Presenelin 1 or Presenilin 2 (PS1 or PS2), Nicastrin, Pen 2 and Aph 1 - with Presenilin representing the catalytic core [6-8]. On the other hand, NFTs are characterized by the accumulation of hyperphosphorylated Tau in neurons [9]. One of the candidates which phosphorylates Tau is Glycogen synthase kinase $3 \beta$ (GSK3 $\beta$ ) [10]. GSK3 $\beta$ is a serine/threonine protein kinase, originally known to inactivate glycogen synthesis. GSK3 $\beta$, an important player in insulin signal cascade [11], is negatively regulated by insulin.

GSK3 $\beta$ also has a wide variety of substrates, other than glycogen synthase, and is expressed in various tissues, with the highest level in the brain. Expression of GSK3 $\beta$ in the brain is considered to be involved in 
abnormal Tau phosphorylation in NFTs [9]. Interestingly, PS1 is also shown to be an unprimed substrate of GSK3 $\beta$ [12], phosphorylated at the serine 353 and 357 residues in the loop domain [13]. Therefore, it is intriguing to investigate the influence of insulin on the function of PS1 through GSK3 $\beta$, which could connect two major pathological hallmarks of $\mathrm{AD}$, namely $\mathrm{A} \beta$ and NFTs.

A potential link between type 2 diabetes and AD has been suggested epidemiologically, clinically and experimentally [14-16], indicating the involvement of perturbed insulin signaling in AD pathogenesis. Interestingly, insulin and the insulin-sensitizing drug have shown to improve cognitive performance in mouse models of $\mathrm{AD}$, as well as in patients with early $\mathrm{AD}$ [17-19]. Although many reports suggest that perturbed insulin signaling could contribute to the AD pathogenesis, direct interactions between insulin signaling and PS1 have not been elucidated so far.

Here, we demonstrate that insulin inhibits PS1 phosphorylation and potentiates PS1/N-cadherin/ $\beta$-catenin complex formation at the cell membrane, subsequently redistributing PS1 to the cell surface via PI3K/Akt signal pathway. Our findings clearly indicate that PS1 is functionally modulated by insulin signaling, thus providing a novel link between glucose metabolism and AD pathogenesis. 


\section{Material and methods}

\section{Plasmid constructs}

The pcDNA3.1-hIR (human Insulin Receptor) construct was a kind gift from Dr. Ikeuchi (Niigata University, Japan) [20].

\section{Cell culture and transfection}

For the establishment of cell lines which stably express hIR (Supplemental Fig. 1), SH-SY5Y (derived from human neuroblastoma) cells were transfected with pcDNA3.1-hIR, using a TransFectin reagent (Bio-Rad) and selected by $300 \mu \mathrm{g} / \mathrm{ml} \mathrm{G418} \mathrm{solution} \mathrm{(nacalai} \mathrm{tesque,} \mathrm{Japan).} \mathrm{Primary} \mathrm{neurons} \mathrm{were} \mathrm{obtained} \mathrm{from} \mathrm{the}$ cerebral cortices of fetal mice (14-16 days' gestation) and cultured with Neurobasal medium containing B-27 supplements and $0.5 \mathrm{mM} \mathrm{L-glutamine} \mathrm{(all} \mathrm{reagents} \mathrm{purchased} \mathrm{from} \mathrm{Invitrogen).} \mathrm{After} 7$ days' culture, cells were used in the experiment.

\section{Antibodies and chemical reagents}

Mouse monoclonal anti-IR was from Neo Markers (Fremont, CA). Rabbit polyclonal anti-Akt, phosphoAkt (S473), phospho-GSK3 $\beta$ (S9) and mouse monoclonal anti-phospho- $\beta$-catenin antibodies were from Cell Signaling Technology. Mouse monoclonal anti-GSK3 $\beta, \mathrm{N}$-cadherin and $\beta$-catenin antibodies were from BD Transduction Laboratories. Mouse monoclonal anti-phospho-serine, $\beta$-actin and A $\beta(6 \mathrm{E} 10)$ antibodies were from SIGMA. Rabbit polyclonal anti-PS1 NTF, goat polyclonal PS1 CTF and phospho-PS1 (S353/357) antibodies were from Santa Cruz. Alexa Fluor 546 anti-mouse IgG and Alexa Fluor 488 anti-goat IgG were obtained from Molecular Probes. Insulin solution was from SIGMA and DMSO was from nacalai tesque.

\section{Western blotting and Immunoprecipitation}


Preparation of protein samples, Western blotting and immunoprecipitation analysis were carried out as described previously [21].

\section{Immunostaining}

Preparation of cell samples and immunostaining analysis was carried out as described previously [22]. The samples were examined using a laser confocal scanning microscope, LSM 510 Pascal (Zeiss).

\section{Aßapplication}

Synthetic A $\beta$ 1-40, 1-42 and control reverse peptides were obtained from Bachem. Each peptide was dissolved in $100 \%$ dimethyl sulfoxide (DMSO), at a concentration of $1 \mathrm{mM} \mathrm{A} \beta$ solution and aliquots were prepared, which were either used fresh or fresh-frozen, and stored at $-80^{\circ} \mathrm{C}$ until use. $\mathrm{A} \beta$ solutions were added to Opti-MEM, to give a final concentration of $1 \mu \mathrm{M}$ A $\beta$ 1-40 or $100 \mathrm{nM}$ A $\beta$ 1-42, respectively. Immediately, SHSY5Y wt IR cells or primary neurons were pre-incubated in the $\mathrm{A} \beta$ containing media for $30 \mathrm{~min}$ at $37^{\circ} \mathrm{C}$. After pre-incubation, the cells were stimulated by $50 \mathrm{nM}$ insulin for $30 \mathrm{~min}$, in the presence of $\mathrm{A} \beta$ (Schematic presentation of this experiment is described in Supplemental Fig. 3A). Characterization of the A $\beta$ species in this experiment was analyzed by Tricine-SDS-PAGE (Supplemental Fig. 3B).

\section{Biotinylation of cell surface proteins}

Preparation of cell samples and biotinylation analysis were carried out as described previously [22]. Precipitated biotinylated proteins were then subjected to Western blotting analysis.

\section{Statistical analysis}


All values are given in means \pm SE. Comparisons were performed using an unpaired Student's t-test. For comparison of multiparametric analysis, one-way factorial ANOVA followed by post hoc analysis by Fisher's PLSD was used. $\mathrm{p}<0.05$ was considered to indicate a significant difference. $\mathrm{n}=4$ indicated four independent experiments. 


\section{$\underline{\text { Results }}$}

\section{Insulin signaling inhibited PS1 phosphorylation.}

To investigate the possibility of direct influence of insulin signaling on PS1, we examined whether activated PI3K/Akt signaling by insulin inhibits GSK3 $\beta$ activity as well as PS1 phosphorylation. In SH-SY5Y wt IR cells, PI3K/Akt pathway was activated by insulin, leading to phosphorylation of GSK3 $\beta$ at serine 9 (Fig. $1 \mathrm{~A}, 2^{\text {nd }}$ and $4^{\text {th }}$ rows). The inhibition of GSK3 $\beta$ activity was confirmed by the detection of phospho- and total levels of $\beta$-catenin (Fig. 1A, $6^{\text {th }}$ and $7^{\text {th }}$ rows) which is a substrate for GSK3 $\beta$-mediated phosphorylation, since GSK3 $\beta$-mediated phosphorylation destabilizes $\beta$-catenin by promoting proteasomal degradation [23]. Accordingly, insulin significantly reduced the level of phosphorylated PS1 in serine 353 and 357 residues (Fig. 1B, D). This result was confirmed by immunoprecipitation assay (Fig. 1C), and immunostaining with phosphospecific anti-PS1 antibody clearly demonstrated that insulin treatment markedly reduced PS1 phosphorylation in the cells (Fig. 1E-H).

\section{Insulin signaling regulates the subcellular localization of PS1.}

We previously reported that PS1 phosphorylation at serine 353 and 357 affects its localization. Phosphorylation at serine 353 and 357 inhibits PS1 binding to N-cadherin/ $\beta$-catenin complex [22]. Since insulin signaling inhibited PS1 phosphorylation, we assumed that insulin would in turn redistribute PS1 to the cell surface. We examined the effect of insulin on PS1/N-cadherin/ $\beta$-catenin complex by immunoprecipitation assay. Insulin treatment dose-dependently increased the binding of PS1 to N-cadherin, as well as to $\beta$-catenin (Fig. 2A, $1^{\text {st }}$ and $2^{\text {nd }}$ rows) in SH-SY5Y wt IR cells (relative phosphorylation ratio of p-GSK3 $\beta$ S9/ GSK3 $\beta$ is described in Supplemental Fig. 2A). This result was also confirmed in mouse cortex primary neurons (Fig. 2B, $2^{\text {nd }}$ and $3^{\text {rd }}$ lane). Several downstream pathways are involved in insulin signaling $[24,25]$. To verify that GSK3 $\beta$, 
which is an immediate downstream target of PI3K/Akt pathway, downregulates the association of PS1 and Ncadherin/ $\beta$-catenin complex, SH-SY5Y wt IR cells were pre-treated with Akt inhibitors (Akt inhibitor IV, X) before insulin treatment. Although the treatment with both inhibitors reduced the binding of PS1 to Ncadherin/ $\beta$-catenin (Fig. 2C), quantitative analysis revealed that Akt inhibitor IV was less effective in phosphorylation of GSK3 $\beta$, compared to Akt inhibitor X (Fig. 2D). On the other hand, we demonstrated that GSK3 $\beta$ inhibitors strengthened the complex as well as insulin in primary neurons (Fig. $2 \mathrm{~B}, 4^{\text {th }}$ and $5^{\text {th }}$ lanes).

We have previously reported that physical interaction between PS1 and N-cadherin/ $\beta$-catenin plays an important role in cell surface expression of PS1/ $\gamma$-secretase [22]. Therefore, we examined the expression level of cell surface PS1 in the presence of insulin by biotinylation assay. As expected, the cell surface PS1 level in insulin-treated cells was higher than that in non-treated ones, confirming that inhibition of GSK3 $\beta$ by insulin redistributes PS1 to the cell surface (Fig. 2E, top row, right lane).

\section{A $\beta$ application affects the state of PS1 phosphorylation and its complex formation.}

Several reports have suggested that $A \beta$ can interfere with insulin signaling [26-28]. Since insulin signaling could decrease the phosphorylation state of PS1, we treated cells with the medium containing $1 \mu \mathrm{M} \mathrm{A} \beta_{40}$ or 100 $\mathrm{nM} \mathrm{A} \beta_{42}$ and examined the state of PS1/N-cadherin/ $\beta$-catenin complex, as well as PS1 phosphorylation. A $\beta$ species in the media were characterized by Tricine-SDS-PAGE (Supplemental Fig. 3B). Both media contained similar species including monomer and SDS-resistant oligomers - dimer, trimer, tetramer and high molecular weight oligomers. Interestingly, treatment with the medium containing either $A \beta_{40}$ or $A \beta_{42}$ increased the level of phosphorylated PS1 (Fig. 3A, top row, $1^{\text {st }}$ and $2^{\text {nd }}$ lanes), suggesting the up-regulation of GSK3 $\beta$ activity (Fig. $3 \mathrm{~A}, 3^{\text {rd }}$ row, $1^{\text {st }}$ and $2^{\text {nd }}$ lanes, Fig. 3B). Moreover, the interaction of PS1/N-cadherin/ $\beta$ catenin was reduced in neurons treated with $\mathrm{A} \beta$-containing medium (Fig. $3 \mathrm{C}, 1^{\text {st }}$ and $2^{\text {nd }}$ rows, $2^{\text {nd }}$ and $3^{\text {rd }}$ lanes), 
compared to reverse $\mathrm{A} \beta$-containing medium (Fig. $3 \mathrm{C}, 4^{\text {th }}$ lane), indicating that soluble forms of $\mathrm{A} \beta$ can enhance PS1 phosphorylation and inhibit the PS1/ N-cadherin/ $\beta$-catenin interaction. 


\section{$\underline{\text { Discussion }}$}

Several lines of evidence suggested a potential link between type 2 diabetes and AD. So far, the causal relationship between them has been investigated by two distinct approaches: the modulation of Tau phosphorylation by GSK3 $\beta$ activity, and A $\beta$ metabolism. In the former, loss of insulin-mediated activation of PI3K and subsequent reduction of phosphorylation of Akt and GSK3 $\beta$ are reported to result in a substantial increase in levels of phosphorylated Tau in the brains of neuron specific IR knockout mice [3]. Abnormal increase in the GSK3 $\beta$ level and activity is actually associated with AD pathophysiology [29]. As for the latter, since it is known that $\mathrm{A} \beta$ is resolved by Insulin-degrading enzyme (IDE), some researchers hypothesize that higher insulin levels in a diabetic condition can induce $A \beta$ accumulation by directly competing with $A \beta$ for IDE, thereby limiting $A \beta$ degradation $[30,31]$. In spite of mounting evidence that insulin signaling dysfunction or insulin resistance are implicated in $\mathrm{AD}$ pathophysiology, it still remains largely unknown how two pathological hallmarks - Amyloid and Tau - are causally related to each other via insulin signaling.

In the present study, we have shown for the first time that insulin-mediated PI3K/Akt signaling decreases the phosphorylation of PS1 and enhances PS1/N-cadherin/ $\beta$-catenin interaction via inhibition of GSK3 $\beta$ activity (Fig. 1 and 2). As shown in Figure 3D, insulin treatment inactivates GSK3 $\beta$, thereby blocking its activity on PS1 phosphorylation. This tightens the binding of PS1 to N-cadherin/ $\beta$-catenin complex, which results in relocalizing PS1 to the cell surface. In contrast, if this pathway fails to phosphorylate GSK3 $\beta$ due to either signaling dysfunction or insulin resistance, GSK3 $\beta$ in an active form tends to phosphorylate PS1, which has less ability to form the complex. Since the total $\beta$-catenin level is affected by the inhibition of GSK3 $\beta$, the increase of PS1/ $\beta$-catenin association could be attributed to the elevation of the total $\beta$-catenin level. However, the total $\mathrm{N}$-cadherin level did not change before and after insulin treatment (Fig. 2) thus, leading us to conclude that insulin increased the association of PS1 to N-cadherin/ $\beta$-catenin complex. 
In our study, acute application of $A \beta$ was sufficient to impair the interaction of PS1 and $N$-cadherin/ $\beta$ catenin, suggesting the possibility that an ample amount of A $\beta$ could lead to aberrant phosphorylation of PS1 in $\mathrm{AD}$ brains, via reduction of insulin signaling (Fig. 3A-C). The media used in our study contained monomers and various SDS-resistant $A \beta$ oligomer species, which were derived from synthetic A $\beta$ (Supplemental Fig. 3). Since several reports suggest that $\mathrm{A} \beta$ oligomers play an important role on insulin signaling [26-28], we assume that the total effect of the $\mathrm{A} \beta$ mixture containing these oligomers has an impact on this signaling as well as on PS1 phosphorylation. In our recent report, we demonstrated that disruption of PS1/N-cadherin/ $\beta$-catenin complex impairs $A \beta$ production but increases the $A \beta 42 / 40$ ratio [4]. Therefore, we postulate that perturbed insulin signaling could play a pivotal role in relocalizing PS1 to the cell surface, which in turn may have an impact on $A \beta$ production and $A \beta 42 / 40$ ratio.

In relevant literature, neuronal insulin receptor-deficient mice (NIRKO) revealed a great increase in the phosphorylation of Tau protein [3]. The decreased phosphorylation of GSK3 $\beta$ observed in these mice results in an increased GSK3 $\beta$ activity and may cause the increase in Tau phosphorylation. However, these mice did not show any special learning deficits or long-term memory disturbance, suggesting that the mere lack of the IR is not sufficient to cause AD-like symptoms. Hence, we hypothesize that molecules downstream from the IR might be involved in actual AD brains, with PS1 being a possible target for connecting two seemingly independent pathological features - Amyloid and Tau pathologies. Further studies are required to clarify the functional interaction between PS1 and insulin signaling in vivo models. Our findings for the first time demonstrated that insulin has a potent effect on the localization of PS1 in neuronal cells. Whether these phenomena are actually involved in the pathology of sporadic AD cases should be elucidated in future studies. Uncovering the mechanism that links diabetes and $\mathrm{AD}$ will be important, as it may provide a therapeutic target. 


\section{$\underline{\text { References }}$}

[1] Hong M, Lee VM. (1997) Insulin and insulin-like growth factor-1 regulate tau phosphorylation in cultured human neurons. J Biol Chem. 272, 19547-19553

[2] Schubert M, Brazil DP, Burks DJ, et al. (2003) Insulin receptor substrate-2 deficiency impairs brain growth and promotes tau phosphorylation. J Neurosci 23, 7084-7092

[3] Schubert, M., Gautam, D., Surjo, D., et al. (2004) Role for neuronal insulin resistance in neurodegenerative diseases. Proc Natl Acad Sci U S A 101, 3100-3105

[4] Uemura, K., Chrstina M.Lill, Mary Banks, et al. (2009) N-cadhrtin-based adhesion enhances Abeta release amd decrease Abeta $42 / 40$ ratio. J.Neurochem 108, 350-360

[5] De Strooper, B., Saftig, P., Craessaerts, K., et al. (1998) Deficiency of presenilin-1 inhibits the normal cleavage of amyloid precursor protein. Nature 391, 387-390

[6] Yu G, Nishimura M, Arawaka S, et al. (2000) Nicastrin modulates presenilin-mediated notch/glp-1 signal transduction and betaAPP processing. Nature 407, 48-54

[7] Francis R, McGrath G, Zhang J, et al. (2002) Aph-1 and pen-2 are required for Notch pathway signaling, gamma-secretase cleavage of betaAPP, and presenilin protein accumulation. Dev Cell 3, 85-97

[8] Goutte C, Tsunozaki M, Hale VA, and Priess JR. (2002) APH-1 is a multipass membrane protein essential for the Notch signaling pathway in Caenorhabditis elegans embryos. Proc Natl Acad Sci U S A 99, 775-9

[9] Grundke-Iqbal, I., Iqbal, K., Quinlan, M., Tung, Y. C., Zaidi, M. S., and Wisniewski, H. M. (1986) Microtubule-associated protein tau. A component of Alzheimer paired helical filaments. J Biol Chem 261, 6084-6089 
[10] Hanger, D. P., Hughes, K., Woodgett, J. R., Brion, J. P., and Anderton, B. H. (1992) Glycogen synthase kinase-3 induces Alzheimer's disease-like phosphorylation of tau: generation of paired helical filament epitopes and neuronal localisation of the kinase. Neurosci Lett 147, 58-62

[11] Cross, D. A., Alessi, D. R., Cohen, P., Andjelkovich, M., and Hemmings, B. A. (1995) Inhibition of glycogen synthase kinase-3 by insulin mediated by protein kinase B. Nature 378, 785-789

[12] Twomey, C., and McCarthy, J. V. (2006) Presenilin-1 is an unprimed glycogen synthase kinase-3beta substrate. FEBS Lett 580, 4015-4020

[13] Kirschenbaum, F., Hsu, S. C., Cordell, B., and McCarthy, J. V. (2001) Substitution of a glycogen synthase kinase-3beta phosphorylation site in presenilin 1 separates presenilin function from beta-catenin signaling. J Biol Chem 276, 7366-7375

[14] Ott, A., Stolk, R. P., van Harskamp, F., Pols, H. A., Hofman, A., and Breteler, M. M. (1999) Diabetes mellitus and the risk of dementia: The Rotterdam Study. Neurology 53, 1937-1942

[15] Biessels, G. J., Staekenborg, S., Brunner, E., Brayne, C., and Scheltens, P. (2006) Risk of dementia in diabetes mellitus: a systematic review. Lancet Neurol 5,64-74

[16] Ho, L., Qin, W., Pompl, P. N., et al. (2004) Diet-induced insulin resistance promotes amyloidosis in a transgenic mouse model of Alzheimer's disease. FASEB J 18, 902-904

[17] Watson GS, Cholerton BA, Reger MA, et al. (2005) Preserved cognition in patients with early Alzheimer disease and amnestic mild cognitive impairment during treatment with rosiglitazone: a preliminary study. Am J Geriatr Psychiatry 13, 950-958

[18] Pedersen WA, McMillan PJ, Kulstad JJ, Leverenz JB, Craft S, and Haynatzki GR. (2006) Rosiglitazone attenuates learning and memory deficits in Tg2576 Alzheimer mice. Exp Neurology 199, $265-273$

[19] Reger MA, Watson GS, Green PS, et al. (2008) Intranasal insulin improves cognition and modulates beta-amyloid in early AD. Neurology 70, 440-448 
[20] Ebina, Y., Edery, M., Ellis, L., Standring, D., Beaudoin, J., Roth, R. A., and Rutter, W. J. (1985) Expression of a functional human insulin receptor from a cloned cDNA in Chinese hamster ovary cells. Proc Natl Acad Sci U S A 82, 8014-8018

[21] Uemura, K., Kitagawa, N., Kohno, R., Kuzuya, A. et al. (2003) Presenilin 1 mediates retinoic acidinduced differentiation of SH-SY5Y cells through facilitation of Wnt signaling. J Neurosci Res. 73, 16675.

[22] Uemura, K., Kuzuya, A., Shimozono, Y., Aoyagi, N., Ando, K., Shimohama, S., and Kinoshita, A. (2007) GSK3beta activity modifies the localization and function of presenilin 1. J Biol Chem 282, 1582315832

[23] Aberle, H., Bauer, A., Stappert, J., Kispert, A., and Kemler, R. (1997) Beta-catenin is a target for the ubiquitin-proteasome pathway. EMBO J 16, 3797-3804

[24] Bevan, P. (2001) Insulin signalling. J Cell Sci 114, 1429-1430

[25] Lizcano, J. M., and Alessi, D. R. (2002) The insulin signaling pathway. Curr Biol 12, 236-238

[26] Townsend, M., Mehta, T., and Selkoe, D. J. (2007) Soluble Abeta inhibits specific signal transduction cascades common to the insulin receptor pathway. J Biol Chem 282, 33305-33312

[27] Zhao, W. Q., De Felice, F. G., Fernandez, S., et al. (2008) Amyloid beta oligomers induce impairment of neuronal insulin receptors. FASEB J 22, 246-260

[28] Lee, H. K., Kumar, P., Fu, Q., Rosen, K. M., and Querfurth, H. W. (2009) The insulin/Akt signaling pathway is targeted by intracellular beta-amyloid. Mol Biol Cell 20, 1533-1544

[29] Bhat, R. V., Budd Haeberlein, S. L., and Avila, J. (2004) Glycogen synthase kinase 3: a drug target for CNS therapies. J Neurochem 89, 1313-1317

[30] Qiu, W. Q., and Folstein, M. F. (2006) Insulin, insulin-degrading enzyme and amyloid-beta peptide in Alzheimer's disease: review and hypothesis. Neurobiol Aging 27, 190-198 
[31] Pasinetti, G. M., and Eberstein, J. A. (2008) Metabolic syndrome and the role of dietary lifestyles in Alzheimer's disease. J Neurochem 106, 1503-1514 


\section{Figure legends}

\section{Fig. 1. Insulin signaling inhibits PS1 phosphorylation.}

$A$. SH-SY5Y wt IR cells were treated with $50 \mathrm{nM}$ insulin for $30 \mathrm{~min}$ (right lane). $B$. Cell lysates were immunoblotted with anti-phospho-PS1 S353/357 (p-PS1 S353/357) antibody. C. Cell lysates were immunoprecipitated with monoclonal phospho-serine antibody, followed by immunoblotting with PS1 Cterminal antibody. $D$. The relative phosphorylation ratio of PS1 was quantified from immunoblotting assay. ( $\mathrm{n}=4, \mathrm{p}=0.008$, Student's t-test) Data were means \pm SE of four independent experiments. $E-H$. SH-SY5Y wt IR cells with or without insulin treatment for 30 min were immunostained with antiphospho-PS1 S353/357 antibody (green). E and G show representative images from cultures in the absence or presence of insulin. $\mathrm{F}$ and $\mathrm{H}$ show high-magnification images of cells contained in the rectangles indicated in $\mathrm{E}$ and G. Scale bar, $20 \mu \mathrm{m}$.

\section{Fig. 2. Insulin signaling regulates the subcellular localization of PS1.}

A. SH-SY5Y wt IR cells were treated with insulin in different concentrations ( $0 \mathrm{nM}, 10 \mathrm{nM}, 50 \mathrm{nM}) .30$ min after treatment, cell lysates were immunoprecipitated with anti-PS1 N-terminal antibody, followed by immunoblotting analysis. Control precipitation was done with normal rabbit IgG (left lane). B. Mouse cortex primary neurons were treated with $50 \mathrm{nM}$ insulin for $30 \mathrm{~min}\left(3^{\text {rd }}\right.$ lane $)$ or $25 \mathrm{mM} \mathrm{LiCl}, 10 \mu \mathrm{M}$ GSK3 $\beta$ inhibitor VIII for 4 hrs $\left(4^{\text {th }}, 5^{\text {th }}\right.$ lanes $)$. $C$. SH-SY5Y wt IR cells were pre-incubated with $1 \mu \mathrm{M}$ Akt inhibitor IV or X for 18 hours. DMSO was used as a negative control. After pre-incubation, these cells were stimulated by $50 \mathrm{nM}$ insulin for $30 \mathrm{~min}$. $D$. The effect of Akt inhibitors on the phosphorylation of GSK3 $\beta$ S9 was quantitatively analyzed. $(\mathrm{n}=3) E$. After treatment with $50 \mathrm{nM}$ insulin for 30 min, cell surface proteins were biotinylated and analyzed by immunoblotting assay. 
Fig. 3. A $\beta$ application affects the state of PS1 phosphorylation and its complex formation.

A. SH-SY5Y wt IR cells were incubated in the medium containing $1 \mu \mathrm{MA} \beta_{40}\left(1^{\text {st }}\right.$ lane $)$ or $100 \mathrm{nM} \mathrm{A} \beta_{42}$ $\left(2^{\text {nd }}\right.$ lane) for $30 \mathrm{~min}$, followed by stimulation with $50 \mathrm{nM}$ insulin for $30 \mathrm{~min}$. Reversed sequence peptide served as a negative control ( $3^{\text {rd }}$ lane). Lysates were probed with anti-phospho-PS1 S353/357 and antiphospho-GSK3 $\beta$ S9 antibodies. B. After insulin stimulation, the phosphorylation ratio of GSK3 $\beta$ S9/ GSK3 3 in the presence of A $\beta$-containing media was quantitatively analyzed $(n=3)$. $C$. Mouse cortex primary neurons were incubated in the same media conditions, followed by $50 \mathrm{nM}$ insulin stimulation. Cell lysates were immunoprecipitated with anti-PS1 N-terminal antibody, followed by immunoblotting analysis. D. Schematic presentation of cellular events caused by insulin. 


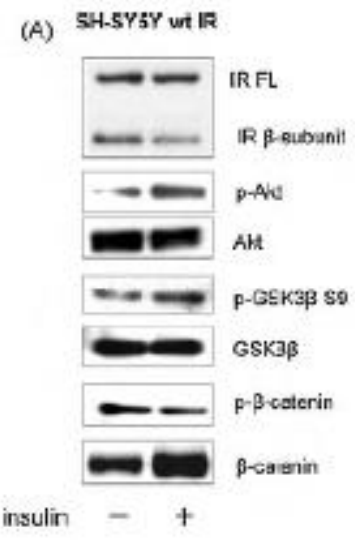

(D) Relative phosphorylation Ratio o1 PS1

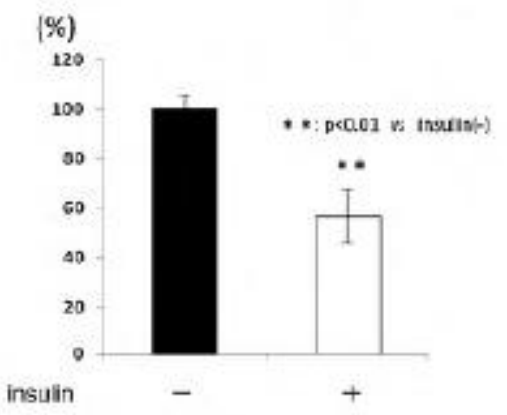

(B) SH.SY5Y wt IR

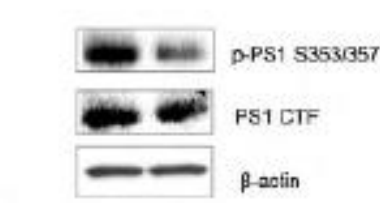

ineun - +
(C)

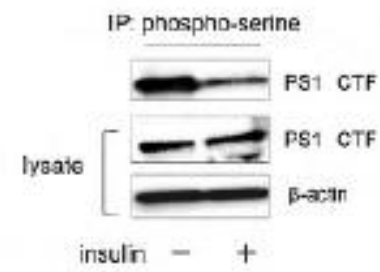

SH-SY5Y un IR

1S: ant-p-PS1 S393/357

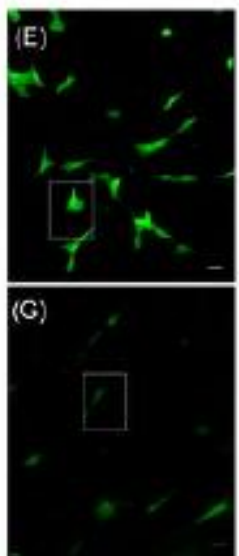

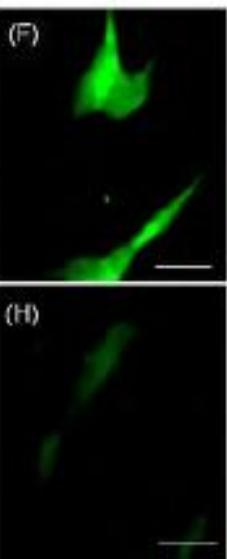

ins.lin .

ingulin +

Figure 1 
(A)

SH.SYSY ut IR

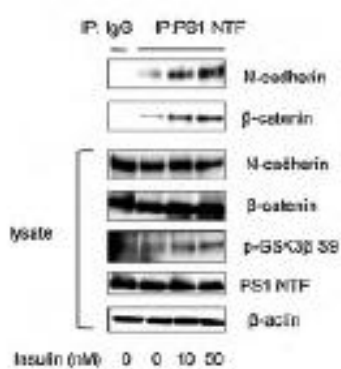

(C)

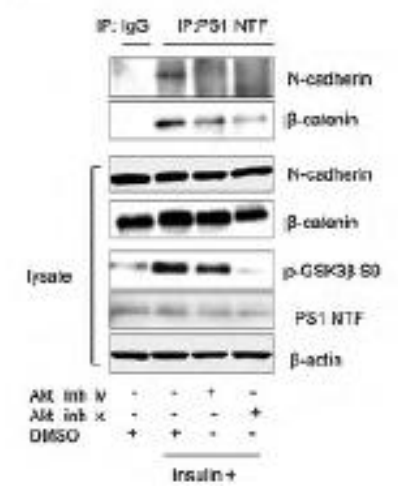

(B)

Mouze cortas primary natron

$$
\begin{aligned}
& \text { ID lac PASINTF }
\end{aligned}
$$

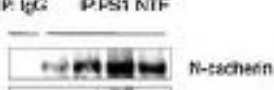

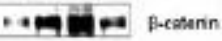

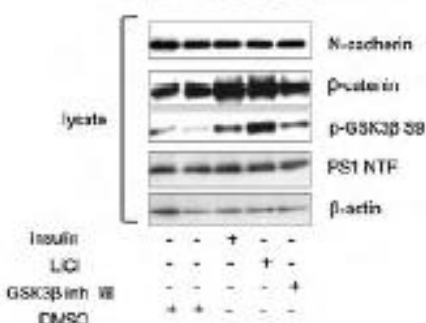

(D)

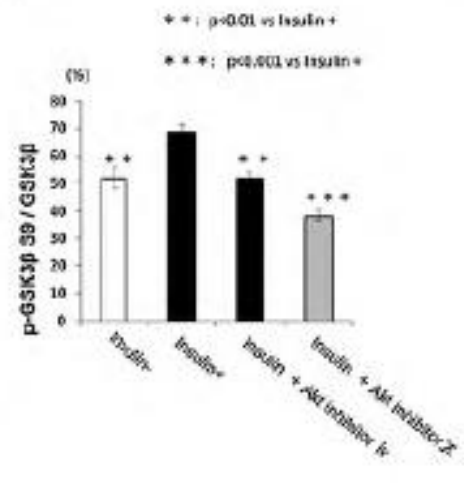

(c) SH-BYS wt IR

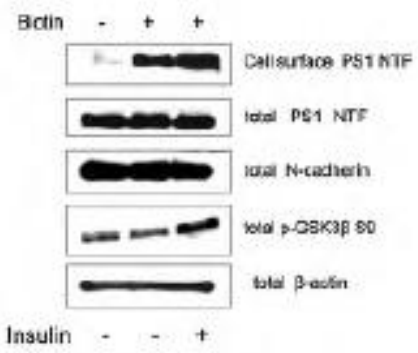

Figure 2 
(A) SH.SYEY wt IR

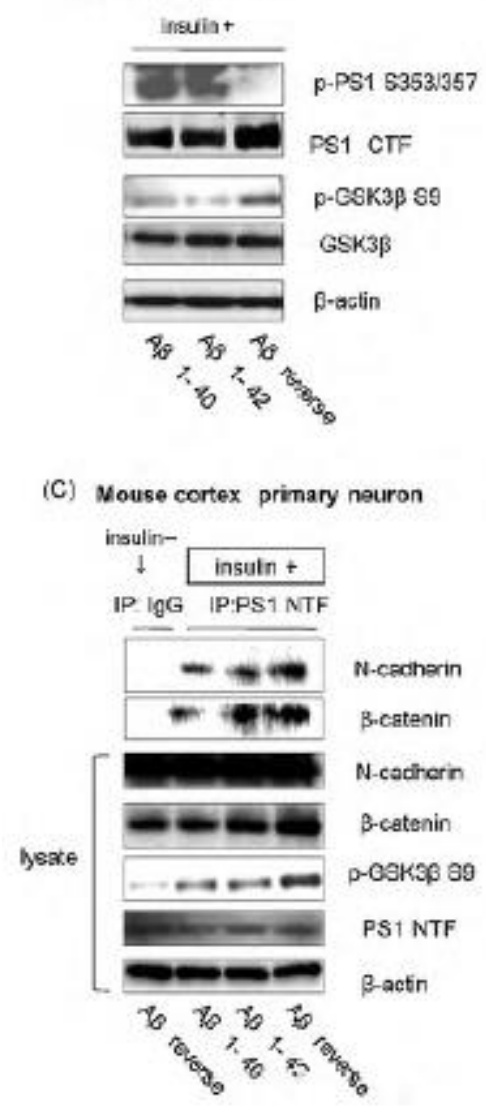

(B) (\%) + * * pepol vs $A B$ reverse /hst

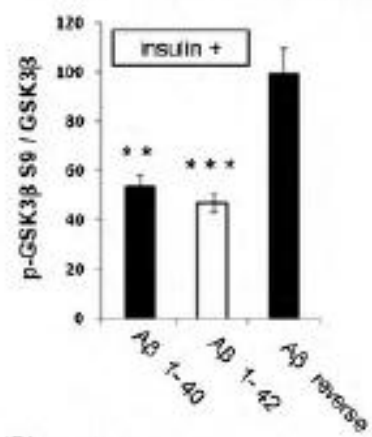

(D)

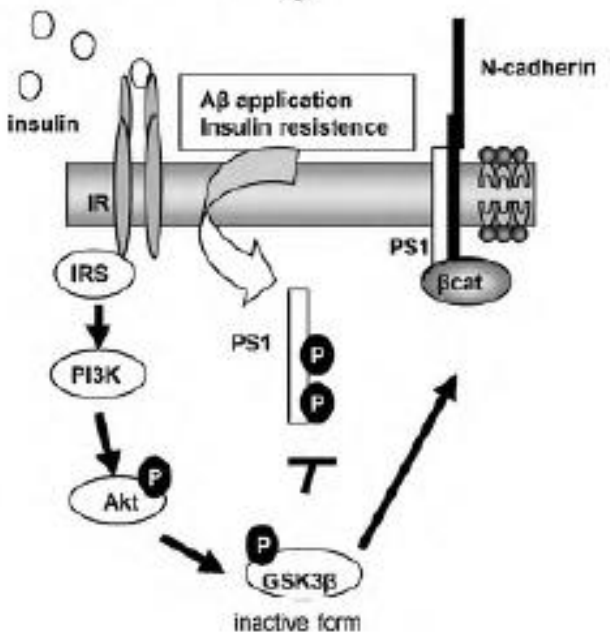

Figure 3 